\title{
O Estágio Supervisionado em Cursos a Distância: Uma Análise da Percepção dos Estagiários do Curso de Administração Pública da Universidade Federal dos Vales do Jequitinhonha e Mucuri - UFVJM
}

The Internship Supervised in Distance Learning: An Analysis of the Perception of the Trainees of the Public Administration Course of the UniversidadeFederal dos Vales do Jequitinhonha e Mucuri - UFVJM

\author{
Naldeir dos Santos Vieira ${ }^{1 *}$ \\ Agnaldo Keiti Higuchi ${ }^{1}$ \\ Adriana Aparecida \\ da Conceição Santos Sá 1 \\ Daniela Cristina da Silveira \\ Campos ${ }^{1}$ \\ Maiara Pereira Teles ${ }^{1}$ \\ ${ }^{1}$ Universidade Federal dos Vales do \\ Jequitinhonha e Mucuri - UFVJM. \\ Rua do Cruzeiro, n.1, Bairro Jardim \\ São Paulo - Teófilo Otoni, MG - Brasil. \\ * naldeir.vieira@ufvjm.edu.br
}

\section{Resumo}

Apesar da relevância do estágio curricular supervisionado para a formação e a inserção de alunos de cursos de graduação no mercado de trabalho, poucos são os estudos que analisam essa prática, principalmente no contexto dos cursos a distância. Em decorrência, este artigo tem como objetivo analisar a satisfação de alunos do curso de Administração Pública da Universidade Federal dos Vales do Jequitinhonha e Mucuri (UFVJM), ofertado na modalidade a distância, em relação ao estágio e suas atitudes em relação a: (i) apoio oferecido pela organização; (ii) teoria-prática; (iii) remuneração; (iv) plano de carreira; (v) acesso a oportunidades de estágio; e (vi) supervisão. Como procedimentos metodológicos, foram aplicados questionários aos alunos do curso matriculados nas disciplinas Estágio Curricular Supervisionado I, II, III, IV no primeiro semestre do ano de 2018 que efetivamente estavam estagiando em organizações públicas. A análise foi realizada por meio de modelos de regressão múltipla. Cabe destacar que os alunos se mostraram satisfeitos com o estágio que estavam desenvolvendo, à exceção dos questionamentos sobre a oportunidade de se envolver em projetos, de serem inseridos no quadro permanente de funcionários e sobre a política de apoio financeiro aos estagiários da concedente.

Palavras-chave: Ensino a distância. Estágio supervisionado. Curso de administração pública. 
The Internship Supervised in Distance Learning: An Analysis of the Perception of the Trainees of the Public Administration Course of the Universidade Federal dos Vales do Jequitinhonha e Mucuri - UFVJM

\section{Abstract}

Despite the relevance of the supervised curricular internship for the training and insertion of students of undergraduate courses in the labor market, few studies are analyzing this practice, especially in the context of distance courses. This paper aims to analyze the satisfaction of students of the Public Administration course of the Universidade Federal dos Vales do Jequitinhonha e Mucuri (UFVIM), offered in the distance modality, in relation to the stage, and their attitudes to (i) support offered by the organization; (ii) theory-practice; (iii) remuneration; (iv) career plan; (v) access to internship opportunities; and (vi) supervision. As methodological procedures, questionnaires were applied to the students of the mentioned course who were enrolled in the Supervised Curricular Internship I, II, III, IV disciplines in the first semester of 2018 and who were effectively attending public organizations. The analysis was performed using multiple regression models. It should be highlighted that the students were satisfied with the stage they were developing, with the exception of questions about the opportunity to get involved in projects, to be included in the permanent staff and on the policy of financial support for trainees.

Keywords: Distance learning. Supervised internship. Public administration course.

\section{Introdução}

Com quatro campi, a Universidade Federal dos Vales do Jequitinhonha e Mucuri (UFVJM) atua na educação a distância (EaD) desde 2010 e, atualmente, tem quatro cursos nessa modalidade: três licenciaturas e o bacharelado em Administração Pública; este é ofertado em 13 polos, com sedes nas cidades de Águas Formosas, Almenara, Araçuaí, Bocaiúva, Janaúba, Mantena, Minas Novas, Nanuque, Padre Paraíso, Pedra Azul, Taiobeiras, Teófilo Otoni e Turmalina (UFVJM, 2018). O quantitativo relevante de alunos que passaram a se formar em Administração Pública fez com que as organizações públicas locais se aproximassem da academia, a oferta de estágio aos alunos regulares do curso é uma das formas mais emblemáticas de interação.

O objetivo é permitir que o estudante integre o que aprendeu de forma teórica com a efetividade da prática do trabalho. É nesse sentido que Scalabrin e Molinari (2013) afirmam que o estágio deve promover a integração do aluno com o mercado de trabalho, já que o estudante pode pôr em prática os conhecimentos teóricos adquiridos academicamente, contrapondo-os à realidade do exercício, lidando com relações interpessoais e responsabilidades diárias, reforçando desse modo sua formação profissional.

No entanto, como pode ser observado em Abreu et al. (2004), existem lacunas entre o que é esperado e o que é ofertado durante a realização do estágio em algumas organizações. Observa-se que, por vezes, o objetivo do estágio tem sido deixado de lado, tornando-o apenas uma modalidade de mão de obra barata, perdendo sua verdadeira essência e objetivo para a formação acadêmica do estudante. Outra controvérsia apontada por Abreu et al. (2004) diz respeito ao fato de, muitas vezes, os profissionais em 
formação executarem atividades que não estão associadas ao seu curso, concluindo o estágio sem adquirir experiência na área e com poucas perspectivas de desenvolvimento.

Nesse contexto, é de suma importância que a instituição de ensino acompanhe esse processo, auxilie na oferta de estágio e se certifique do cumprimento do seu objetivo, assim como é obrigação da organização concedente oferecer instalações que proporcionem aos estagiários desenvolver atividades que permitam a aprendizagem social, profissional e cultural, além de disponibilizar um profissional do seu quadro de pessoal com experiência ou formação acadêmica na área para que possa orientar e supervisionar o estagiário (Brasil, art. $5^{\circ} \S 3^{\circ}$ da Lei 11.788/08).

Poucos estudos sobre estágio supervisionado são encontrados, apesar da evolução e ampliação de cursos a distância no Brasil. Há também falta de relatos da orientação de estágio em cursos da área de Gestão. Assim, faz-se necessário compreender como tem sido essa prática em cursos a distância no país (Barbosa, 2018). Ademais, é relevante verificar se para os alunos do curso a distância em Administração Pública da UFVJM essa etapa tem cumprido corretamente seu objetivo. Destarte, o presente trabalho tem como objetivo analisar a satisfação em relação ao estágio e as atitudes dos estagiários do referido curso em relação ao (i) apoio oferecido pela organização; (ii) à teoria-prática; (iii) à remuneração; (iv) ao plano de carreira; (v) ao acesso a oportunidades de estágio; e (vi) à supervisão.

Com esse intento, foram aplicados questionários aos alunos matriculados nas disciplinas Estágio Curricular Supervisionado I, II, III, IV do curso citado no primeiro semestre de 2018 que estagiavam em organizações públicas do entorno de cinco polos de ensino a distância da UFVJM.

\section{O Estágio Supervisionado}

Até meados de 1960, o estágio de estudantes era desenvolvido de modo informal e tratado como troca de favores entre empresários amigos de modo a permitir que seus filhos pudessem ser introduzidos no mundo do trabalho. Só a partir da segunda metade do século XX, quando o estágio de estudantes passou a ser uma ação organizada e frequente no meio empresarial, o governo passou a regulamentar essa relação visando dar à empresa o incentivo necessário para que mais estudantes fossem recebidos para vivenciar práticas que não encontrariam na escola (Leal, 2006).

Uma característica que define o estágio até os dias atuais, que já nessa época era entendimento comum, é que estudantes deveriam exercitar no mercado de trabalho a teoria que recebiam em suas escolas. Com isso, teriam a oportunidade de conhecer o funcionamento das organizações, as relações entre empregados, questões de horário, responsabilidade, subordinação e hierarquia, produção e resultado.

Inicialmente, esse exercício da teoria na prática aconteceria por meio de "atividades múltiplas, seguindo critérios mais produtivos, atendendo em primeiro lugar às necessidades e aos interesses empresariais" (Leal, 2006, p. 166).

Essa situação criou um quadro de ressentimentos mútuos: a escola reclamava da empresa por sua atitude arrogante e insensível ao aprimoramento das relações entre a educação e o trabalho; a empresa considerava que a escola olhava demais para o próprio umbigo, não tinha iniciativa e carecia de objetividade na relação com o meio produtivo (Leal, 2006). Ou seja, a presença do estagiário nas organizações desde sempre foi tema de questionamentos por parte da concedente, dos estagiários e até mesmo do governo, que regula essa relação estagiário-concedente-escola.

Foi criada e aos poucos aperfeiçoada uma legislação voltada à regulação do estágio. A primeira normativa foi publicada em 1967, quando o Ministério do Trabalho, por meio de uma portaria, criou benefícios de ordem trabalhista para a empresa receber estagiários e passou a exigir seguro contra acidentes pes- 
soais em favor do estagiário durante sua permanência na empresa. Em 1977, foi criada a Lei n 6.494/77, que buscou ajustar a atuação do estagiário na empresa, que até então "tinha adquirido contornos muito produtivos e pouco adequados para seu desenvolvimento pessoal e futuro profissional" (Leal, 2006, p. 167). Em janeiro de 1985, o Decreto $n^{\circ} 87.497 / 85$ passou a vigorar para a regulamentação do estágio, no qual "a interveniência da escola no processo ficou clara e obrigatória, as condições para a realização do estágio passaram a ser institucionalizadas e a assinatura da escola no termo de compromisso de estágio, que rege a relação e a permanência do estudante na empresa, tornou-se obrigatória".

Para Leal (2006), um estágio é tecnicamente adequado quando: a) há um objetivo claro e condizente com a presença do estagiário na empresa; b) as atividades desenvolvidas pelo estagiário têm vinculação com seu curso e há relação direta com o objetivo estabelecido; c) os supervisores da empresa e da escola estão identificados e participam construtivamente das atividades desenvolvidas pelo estagiário; d) o estagiário participa das atividades de desenvolvimento promovidas pela empresa; e) se o estágio é de longa duração, deve ser observado um crescimento claro na complexidade das atividades desenvolvidas pelo estagiário; e f) permitir ao estagiário obter resultados.

Da perspectiva de Albuquerque e Silva (2006), para que o estágio alcance sua finalidade, associando o processo educativo à aprendizagem, é necessário que seja planejado, executado e avaliado por meio de diretrizes bem definidas. Ademais, o estágio deve estar em consonância com os pressupostos que norteiam o projeto do curso e com a legislação que rege o assunto. Além disso, é necessária plena sintonia entre o trabalho desenvolvido nas universidades e os alunos, para que eles possam estar preparados para atender às exigências do mercado de trabalho.

O estudante, ao iniciar o estágio, almeja, além da aprendizagem prática, uma chance de inserção no mercado de trabalho. Percebe-se isso quando o estágio passa a ser até mais importante que o próprio curso, na medida em que o estudante entende que o aprendizado prático tem maior reconhecimento, e a cobrança de horário e disponibilidade e suas responsabilidades são as mesmas de um trabalhador efetivo (Oliveira et al., 2007).

Para as organizações concedentes, a oferta de estágio é uma oportunidade de encontrar pessoas qualificadas, já que muitos universitários procuram por essa prática profissional (Araújo et al., 2013). No entanto, conforme Oliveira et al. (2007), ainda é um grande desafio para os estudantes do curso de Administração conseguir uma vaga num mercado de trabalho que, muitas vezes, exige currículo com experiência prática.

Apesar da dificuldade apontada, Oliveira et al. (2007) afirmam que o estágio obrigatório vem se tornando um importante meio progressivo de inserção profissional. Nesse contexto, o estágio supervisionado tem grande importância para a organização no que diz respeito à troca de experiências entre os ambientes envolvidos, meio acadêmico e profissional, além de possibilitar o fornecimento de talento humano, em que o estudante oferece para a organização todo um arcabouço teórico da academia para a dinâmica do mercado. Além de contribuir para a formação do capital humano da organização, o estágio supervisionado é de suma importância para a cultura organizacional da instituição concedente, permitindo que o estagiário tenha contato direto com ela, conhecendo os princípios que a fundamentam, auxiliando no desenvolvimento da ética profissional, tornando desnecessários grandes investimentos em programas de socialização de um novo funcionário. Nesse período de interação com o estudante, a organização pode avaliar e treinar um potencial futuro funcionário de forma eficaz e econômica, o que lhe permite investir em novos talentos, adquirir conhecimento e renovar sua equipe (Aquino; Tomassini, 2008).

Como foi evidenciado no estudo desenvolvido por Oliveira et al. (2007, p. 14) com alunos do curso de graduação em Administração, a maioria dos estagiários carrega um sentimento de satisfação com relação à execução de estágios, mesmo quando suas atividades extrapolam o que estava acordado no termo de estágio, levando a crer que "a experiência é encarada como um processo de aprendizagem". Custódio e Carrão (2012), ao estudarem o impacto do estágio na formação do administrador, obtiveram resultados 
em que as expectativas da maior parte dos estudantes quanto à qualificação oferecida no curso para a realização do estágio foram positivas, tendo sido o conteúdo das disciplinas e as habilidades propostas pelo projeto pedagógico do curso favoráveis para sua prática profissional.

\section{O Estágio Supervisionado no Curso de Administração Pública na Modalidade EaD}

Para Martins et al. (2017) e Barbosa (2018), na EaD, mais do que no ensino presencial, é necessário dar atenção ao estágio, principalmente no que se refere à supervisão do estagiário, já que o aluno não está tão perto da Instituição de Ensino.

O estudante em EaD tem anseios e intenções que se diferenciam do estudante tradicional; isso deve ser considerado em todo o processo de ensino-aprendizagem. Geralmente o estudante em cursos na modalidade a distância tem motivações diferentes: falta de tempo para frequentar aulas, distância de instituições de ensino e possibilidade de entrar em contato com pessoas de diferentes classes sociais, culturais, econômicas e experimentais. Além disso, a EaD exige, pela diversidade de estudantes, que sejam respeitados os diversos estilos e ritmos de aprendizagem, que sejam estabelecidos conteúdos e sequências de atividades que levem à autoaprendizagem e que seja criado suporte adequado ao estudante (Pimentel, 2006).

Esse suporte ao acadêmico "é de grande valor, devendo ser feito pelos meios mais variados possíveis para que atenda a necessidade de cada um deles, respeitando a sua região, a sua cultura e as dificuldades enfrentadas pela comunidade onde vive" (Bittencourt, 2011, p. 3).

Essa é uma regra comum na atividade de estágio e, na Resolução $n^{\circ}$ 32- CONSEPE da UFVJM, de 21 de novembro de 2008, adverte-se que "em qualquer uma das modalidades, o estágio será realizado sob orientação de um professor, escolhido pelo discente entre os docentes do curso ou designado pelo coordenador de curso, e acompanhado de um supervisor na Instituição Concedente".

Na modalidade a distância, o curso de Administração Pública da UFVJM conta com a colaboração de um professor/orientador de estágio. Além disso, o curso possui um professor das disciplinas de estágio e um coordenador de estágio, auxiliados por um tutor que dá suporte direto aos alunos. O professor/ orientador tem a função de possibilitar orientações específicas sobre o estágio a ser desenvolvido; o coordenador tem a função de orientar no cumprimento da legislação própria de estágio, assim como nos detalhes estabelecidos no projeto pedagógico do curso. Nesse caso, o aluno deve preferencialmente realizar o estágio em órgãos da administração pública. O Estágio Supervisionado obrigatório tem carga horária de 300 horas, divididas em quatro momentos distintos com 75 horas cada um (Estágio I, II, III, IV).

Conforme ressaltam Ferreira e Santos (2017, p. 45), a legislação que discorre sobre o estágio não estipula que atividades devem ser desenvolvidas pelos estagiários, mas é clara ao definir que tais atividades devem estar ligadas à sua graduação e o estágio deve contribuir para a formação acadêmica e profissional de quem o realiza, "proporcionando ao acadêmico a profissionalização por intermédio de vivências práticas".

Nesse sentido, Bittencourt (2011, p. 7) afirma que, na educação a distância, a "atividade de estágio deve ser vista como uma prática que busca a produção de conhecimento e experiências que levem o acadêmico muito além da 'aplicação' de informação e de conteúdo repassados pelo professor/tutor".

O caráter especial da prática do estágio na educação a distância está no caráter social e humanitário dessa atividade, tendo em vista que numa modalidade de educação em que o ensino é transmitido quase na sua totalidade por meio de meios virtuais e de telecomunicações, surge o 
estágio como a fase desse ensino que aproxima efetivamente o acadêmico do meio social, levando-o além da instituição de ensino e dos seus colegas, dando ênfase à relação e interação humanas (Bittencourt, 2011, p. 8).

No entanto, se para o estudante tradicional há dificuldades para encontrar e realizar um estágio que efetivamente contribua para a futura prática profissional, para o estudante da EaD o processo é ainda mais complexo, pela distância entre as organizações concedentes e a instituição de ensino (Barbosa, 2018). Distância geográfica que pode resultar em dificuldade de comunicação e alinhamento entre o que a escola entende por estágio e o que a organização concedente está a oferecer ao estagiário.

\section{Procedimentos Metodológicos}

A presente pesquisa é caracterizada como descritiva e quantitativa (Gil, 2008), tendo como foco principal a percepção dos estudantes do curso de Administração Pública da UFVJM que estavam cursando as disciplinas de Estágio Supervisionado e atuando efetivamente como estagiário em organizações públicas. Os dados foram levantados por meio de questionários e analisados estatisticamente.

Além das questões relacionadas ao perfil dos respondentes e aspectos sugeridos para melhorias, o instrumento de coleta de dados incluiu questões com o objetivo de mensurar os seguintes aspectos relacionados à execução do estágio: (i) apoio oferecido pela organização; (ii) relação teoria-prática; (iii) remuneração; (iv) plano de carreira; (v) acesso a oportunidades de estágio; e (vi) supervisão.

No aspecto apoio oferecido pela organização, as questões abordavam socialização, motivação, treinamento, supervisão e desenvolvimento. No aspecto relação teoria-prática, as questões se relacionaram à aplicação, nas atividades práticas desenvolvidas, dos conhecimentos teóricos vistos nas disciplinas. No aspecto remuneração, procurou-se avaliar o valor da remuneração e a política de remuneração adotada pela organização concedente. No aspecto plano de carreira, as questões abordavam a oportunidade de efetivação. No aspecto acesso à oportunidade de estágio, a pergunta procurou mensurar a dificuldade em encontrar estágio. Por fim, no aspecto supervisão, mensurou-se o alinhamento entre a formação do supervisor e a área de conhecimento das atividades de estágio.

O aspecto (i) é mensurado por dez questões; o aspecto (ii), por seis questões; os aspectos (iii) e (iv) são mensurados por duas questões; e os aspectos (v) e (vi), por uma questão. Foram inseridas também duas perguntas com o objetivo de mensurar a satisfação geral do aluno com o estágio. A primeira indagou sobre o atendimento das expectativas do aluno com relação ao estágio; a segunda, sobre a propensão a optar pela mesma organização caso fosse possível repetir o estágio.

Foram enviados aos 52 alunos matriculados nas disciplinas Estágio Curricular Supervisionado I, II, III e IV de cinco polos de ensino (Águas Formosa, Padre Paraíso, Nanuque, Turmalina e Taiobeiras) e-mails com o link para o preenchimento do questionário elaborado na plataforma surveymonkey®. Os alunos que já eram funcionários públicos e solicitaram aproveitamento de atividades profissionais como estágio foram excluídos do universo da pesquisa. Desse universo, foi obtido um percentual de $62 \%$ de retorno, com a obtenção de 32 respostas.

De posse dos dados, eles foram analisados com o auxílio do pacote estatístico SPSS®. Os dados faltantes em cada caso foram completados com a média dos valores respondidos. Primeiramente, foi feita análise fatorial confirmatória para verificar se as perguntas relacionadas a cada aspecto tiveram maiores cargas fatoriais $(>0,6)$ no mesmo fator, a fim de testar a validade discriminante das perguntas. Os critérios para validação do modelo fatorial foram índice do teste Kaiser-Meyer-Olkin $(K M O)>0,6$ e significância do 
teste de Bartlett <0,05. Em seguida, foi feita análise de modelos de regressão múltipla, tendo o primeiro modelo como variável dependente a questão sobre atendimento das expectativas e o segundo modelo a questão sobre a propensão a optar pela mesma empresa em novo estágio. As variáveis independentes são representadas por todas as outras. O critério para o teste de significância dos modelos é $p$ valor $<0,1$. (Hair Jr. et al., 2005).

\section{Resultados}

Para atendimento do objetivo deste estudo, foi feita análise fatorial confirmatória para a verificação dos fatores, tendo cada questão apresentado maior fator de carga. Inicialmente, são expostos os resultados das análises de frequência, mostrando o perfil dos respondentes, tipo de instituição em que estagiou, área de atuação no estágio, atividades desenvolvidas, disciplinas que mais contribuíram para o estágio e sugestões de melhoria.

Em relação ao perfil dos respondentes, 56,3\% estão na faixa etária entre 31 e 40 anos. À exceção de um, com 67 anos, os demais têm entre 21 e 30 anos. Entre os entrevistados, $62,5 \%$ são do sexo feminino e $50 \%$ afirmaram estagiar em Prefeituras Municipais.

Não foi identificada concentração de estagiários em cidades específicas; tal resultado é esperado, posto que a pesquisa foi feita com alunos de cinco polos de ensino diferentes. Foram citadas organizações concedentes de 14 cidades localizadas no norte e nordeste mineiro.

Entre os setores em que os alunos atuaram como estagiários, foram destacadas as áreas: administrativas (18,8\%), de secretaria (5\%) e de licitações (5\%). Nos diferentes setores em que atuaram, foi promovida uma diversidade de atividades. O atendimento ao público e as atividades relacionadas a arquivamentos, organização e elaboração de documentos oficiais foram as mais citadas, corroborando os achados de Abreu et al. (2004) em outros contextos. Por mais que o curso de Administração Pública busque a formação de profissionais que exerçam atividades no nível estratégico, este estudo identificou que a maioria executa, como estagiários, atividades operacionais.

Posteriormente, os estagiários foram questionados sobre a percepção que tinham em relação ao estágio que estavam desenvolvendo. Foi elaborada uma matriz com 23 afirmativas, e os respondentes deveriam manifestar concordância ou discordância delas. Nessa escala, o grau um significava "discordo totalmente" e o grau cinco corresponde a "concordo totalmente". Na Tabela 1 são apresentadas as médias obtidas em cada afirmativa.

Os resultados mostram que os estagiários, de modo geral, se manifestaram satisfeitos com estágio que estavam realizando, corroborando os achados de Oliveira et al. (2007) e Custódio e Carrão (2012). No entanto, grande parte se mostrou insatisfeita em três aspectos: oportunidade de desenvolver algum projeto (oportunidade de projeto); oportunidade de inserção no quadro permanente de pessoal da concedente (oportunidade de efetivação); e política de oferta e definição de valor de auxílio financeiro ao estagiário (política de remuneração justa). A média baixa das respostas à afirmativa oportunidade de projeto faz sentido na medida em que as atividades citadas como desenvolvidas dificilmente permitem aos estagiários a prática de ações estratégicas. No que se refere à oportunidade de efetivação, os dados vão de encontro do que é proposto por Oliveira et al. (2007) e Bittencourt (2011), talvez pela peculiaridade da administração pública, que se dá em um contexto em que se deve privilegiar a realização de concursos públicos como estratégia para o recrutamento e a seleção de recursos humanos. 
Tabela 1: Concordância com afirmativas sobre a prática do estágio

\begin{tabular}{|c|c|c|}
\hline Pergunta & Média & $\sigma$ \\
\hline $\begin{array}{l}\text { As atividades realizadas durante o período do estágio tinham relação com o curso em } \\
\text { que estou inserido. }\end{array}$ & 4,53 & 0,95 \\
\hline O supervisor do estágio tem formação ou experiência na área administrativa. & 4,53 & 1,08 \\
\hline $\begin{array}{l}\text { Considero que os demais integrantes da organização concedente foram atenciosos } \\
\text { comigo durante a realização do estágio. }\end{array}$ & 4,53 & 0,76 \\
\hline $\begin{array}{l}\text { A instituição concedente disponibilizou equipamentos e materiais que permitiram a } \\
\text { realizaçâo de minhas atividades. }\end{array}$ & 4,50 & 1,02 \\
\hline $\begin{array}{l}\text { A instituição concedente permitiu meu contato com o supervisor para troca de infor- } \\
\text { mações (feedback) e auxílio na realização das atividades propostas. }\end{array}$ & 4,44 & 1,13 \\
\hline $\begin{array}{l}\text { A instituição concedente forneceu informações necessárias à realização das ativida- } \\
\text { des atribuídas a mim. }\end{array}$ & 4,41 & 1,04 \\
\hline $\begin{array}{l}\text { No decorrer do estágio, houve aplicação do conhecimento teórico adquirido por mim } \\
\text { durante a realização das atividades. }\end{array}$ & 4,41 & 0,84 \\
\hline $\begin{array}{l}\text { Caso pudesse voltar atrás, optaria novamente por estagiar na organização onde } \\
\text { estagiei. }\end{array}$ & 4,35 & 1,17 \\
\hline $\begin{array}{l}\text { Considero ter obtido com o estágio conhecimentos novos sobre administração públi- } \\
\text { ca ainda não acessados na graduação. }\end{array}$ & 4,34 & 0,90 \\
\hline $\begin{array}{l}\text { A instituição concedente proporcionou supervisão, auxiliando-me no desenvolvimen- } \\
\text { to das atividades. }\end{array}$ & 4,31 & 1,20 \\
\hline $\begin{array}{l}\text { Considero que o coordenador de estágio deu as orientações necessárias para o bom } \\
\text { andamento do estágio realizado. }\end{array}$ & 4,31 & 1,03 \\
\hline $\begin{array}{l}\text { Considero que o tutor da disciplina Estágio Supervisionado deu as orientações neces- } \\
\text { sárias para o bom andamento do estágio realizado. }\end{array}$ & 4,31 & 1,09 \\
\hline Considero que o estágio desenvolvido atendeu às minhas expectativas. & 4,28 & 1,05 \\
\hline Durante o período de estágio, a organização concedente procurou me manter motivado. & 4,28 & 0,96 \\
\hline $\begin{array}{l}\text { A organização concedente promoveu minha socialização organizacional, visando à } \\
\text { minha ambientação, apresentando a missão, objetivos, políticas da organização e a } \\
\text { equipe de trabalho. }\end{array}$ & 4,25 & 0,98 \\
\hline $\begin{array}{l}\text { Foi fácil conciliar as atividades desenvolvidas no estágio com o estudo das disciplinas } \\
\text { teóricas do curso. }\end{array}$ & 4,13 & 0,98 \\
\hline $\begin{array}{l}\text { A instituição concedente proporcionou treinamentos que possibilitaram meu desen- } \\
\text { volvimento profissional. }\end{array}$ & 4,06 & 1,19 \\
\hline A organização concedente me ofereceu meios para o desenvolvimento profissional. & 4,06 & 1,24 \\
\hline A instituição concedente me inseriu em projetos e campanhas que desenvolve. & 3,81 & 1,08 \\
\hline Foi fácil obter estágio nas organizações públicas da minha região. & 3,50 & 1,27 \\
\hline Durante o estágio tive oportunidade de desenvolver algum projeto. & 2,87 & 1,38 \\
\hline $\begin{array}{l}\text { A organização concedente ofereceu oportunidades para a minha inserção em seu } \\
\text { quadro permanente de recursos humanos. }\end{array}$ & 2,77 & 1,52 \\
\hline $\begin{array}{l}\text { Considero justas a política de oferta e a definição do valor do auxílio financeiro que, } \\
\text { por ventura, tenha recebido da concedente na condição de estagiário. }\end{array}$ & 1,94 & 1,68 \\
\hline Recebi auxílio financeiro por parte da concedente para a realização do estágio. & 1,50 & 1,34 \\
\hline
\end{tabular}

Para averiguar a associação entre o conhecimento teórico obtido no curso e a aprendizagem prática com o estágio desenvolvido, os alunos foram questionados sobre até cinco disciplinas que mais contribu- 
íram para o bom andamento das atividades desenvolvidas. Observou-se que as disciplinas mais citadas foram Teorias da Administração (25\%), Informática para Administradores (25\%), Gestão de Pessoas no Setor Público (21,8\%), Políticas Públicas e Sociedade (21,8\%) e Redação Oficial (21,8\%). Novamente foi obtido alinhamento entre as atividades que os estagiários desenvolvem e o conteúdo abordado nas disciplinas citadas. Cabe destacar as disciplinas Informática para Administradores e Redação Oficial, cujos conteúdos podem ter facilitado a elaboração de relatórios e documentos oficiais e a alimentação de sistemas de informações gerenciais das organizações concedentes.

Por fim, foi solicitado aos estagiários que apontassem algumas medidas que podem ser implementadas para a melhoria da prática de estágio no curso de Administração Pública em EaD da UFVJM. Os principais apontamentos foram: responder com maior brevidade a dúvidas dos alunos (5 respondentes); meIhorar as instruções sobre a documentação necessária à realização do estágio (4 respondentes); agilizar a entrega dos documentos assinados pela instituição de ensino (3 respondentes); e ampliar a interação entre as organizações públicas e a universidade para facilitar a inclusão dos estagiários (3 respondentes). Quatro estagiários não propuseram melhorias por se considerarem satisfeitos com a forma como o estágio é gerido no curso e onze não responderam a essa questão.

Uma vez expostos os resultados das análises de frequência, foram iniciadas as análises estatísticas das características dos estágios oferecidos, com o estudo das variáveis independentes que levam à satisfação do estagiário, neste estudo representadas pelas variáveis dependentes atendimento das expectativas e opção pela mesma organização para novo estágio.

\subsection{Análise fatorial confirmatória}

A análise fatorial teve como objetivo testar a validade discriminante das perguntas, ou seja, verificar se para cada pergunta havia somente um componente específico. Essa análise foi feita com as seguintes características: método de extração por análise de componentes principais e rotação varimax utilizando matriz de correlação. Os testes KMO e Bartlett apresentaram os resultados mostrados na Tabela 2.

Tabela 2: Teste KMO e Bartlett de adequação de amostra

\begin{tabular}{l|c|c}
\hline \multicolumn{2}{l|}{ Kaiser-Meyer-Olkin } & 0,637 \\
\hline \multirow{2}{*}{ Bartlett's } & & 535,281 \\
\cline { 2 - 3 } & df & 231 \\
\cline { 2 - 3 } & Sig. &, 000 \\
\hline
\end{tabular}

Os resultados indicam que a amostra é adequada para a análise, pois atende aos critérios de validação. Em seguida foi calculada a matriz de componentes rotacionados. Como esperado, a análise retornou seis fatores; cada questão apresentou carga fatorial maior nos fatores que representam os aspectos a que pertencem. As dez questões relacionadas ao aspecto (i) apresentaram maior carga fatorial no fator 1 . 0 mesmo aconteceu nos aspectos (ii), (iii) e (iv). O aspecto (v), relacionado à facilidade de obter estágio, carregou somente no fator 5 , e o aspecto (vi), sobre a supervisão com formação, carregou somente no fator 6. Esses resultados confirmam, assim, a correta discriminação das questões em torno de cada aspecto. Uma vez comprovada a validade discriminante, foi feita a análise de regressão para levantar os antecedentes da satisfação com o estágio.

\subsection{Análise de regressão múltipla}

Foram testados dois modelos. O primeiro teve como variável dependente o atendimento da expectativa com o estágio; o segundo, a variável opção por fazer o estágio novamente na mesma organização. Os 
resultados do teste de significância e de ajustamento do modelo por meio do coeficiente de determinação

$\left(R^{2}\right)$ do primeiro modelo são mostrados na Tabela 3.

Tabela 3: Teste de significância e ajustamento do modelo 1

\begin{tabular}{c|c|c}
\hline $\mathbf{R}^{2}$ ajustado & $\mathbf{F}$ & Sig. \\
\hline 0,879 & 11,21 & 0,000 \\
\hline
\end{tabular}

Os resultados da Tabela 3 indicam que o modelo é significativo $(p<0,05)$ e explica 87,9\% da variância da variável Atendimento das expectativas. Em seguida, foram calculados os coeficientes e significâncias por meio de teste t de cada variável independente (Tabela 4).

Tabela 4: Coeficiente e significâncias do modelo 1

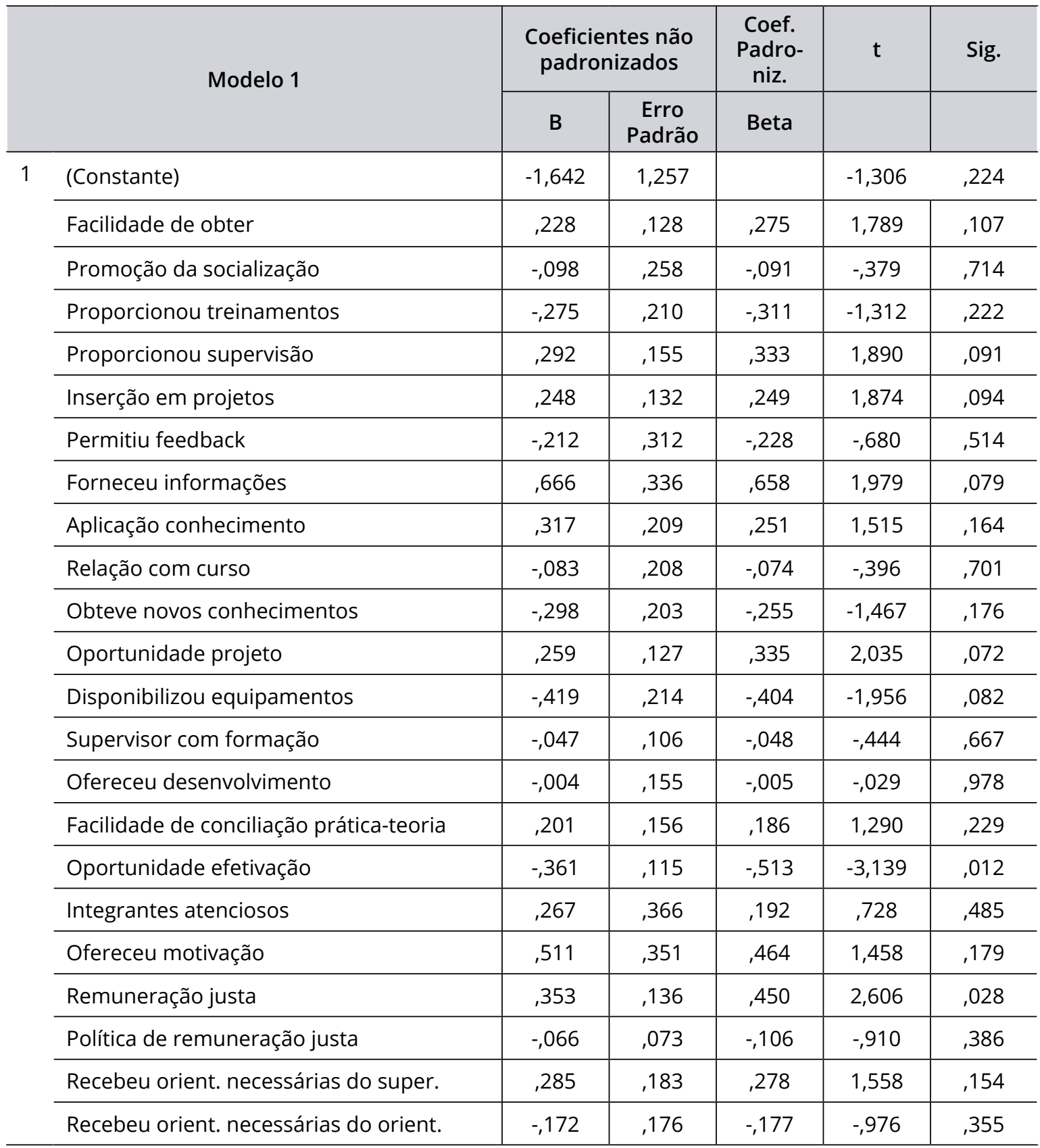

a: Variável dependente Atendimento das expectativas. 
Os resultados indicam que somente as variáveis Proporcionou supervisão (Beta $=0,33, p<0,1$ ), Inserção em projetos (Beta $=0,25, p<0,1$ ), Forneceu informações (Beta $=0,66, p<0,1$ ), oportunidade em projeto (Beta $=0,34, p<0,1$ ), Disponibilizou equipamento (Beta $=-0,4, p<0,1$ ), Oportunidade de efetivação (Beta $=-0,513, p<0,05$ ) e Remuneração justa (Beta $=0,45, p<0,05$ ) apresentaram relações significativas com a variável Atendimento das expectativas.

Assim, a variável dependente Atendimento das expectativas é explicada pelas seguintes variáveis independentes, por ordem de influência: Forneceu informações, Remuneração justa, Disponibilizou equipamento, Oportunidade em projeto, Proporcionou supervisão, Inserção em projetos e, de forma negativa, Oportunidade de efetivação. A Tabela 5 expõe os resultados do teste de significância e ajustamento do segundo modelo.

Tabela 5: Teste de significância e ajustamento do modelo 2

\begin{tabular}{c|l|l}
\hline $\mathrm{R}^{2}$ Ajustado & $\mathrm{F}$ & Sig. \\
\hline 0,773 & 5,79 & 0,005 \\
\hline
\end{tabular}

Os resultados da Tabela 5 indicam que o modelo é significativo $(p<0,05)$ e explica 77,3\% da variância da variável opção pela mesma organização para novo estágio. Em seguida, foram calculados os coeficientes e significâncias por meio de teste t de cada variável independente. Os resultados são mostrados na Tabela 6.

Pelos resultados apresentados na Tabela 6, percebe-se que as variáveis Proporcionou supervisão (Beta $=0,55, p<0,05)$, Oportunidade de efetivação (Beta $=-0,511, p<0,05)$, Inserção em projetos (Beta $=0,38$, $p<0,1$ ) e Remuneração justa (Beta $=0,496, p<0,1$ ) apresentaram relações significativas com a variável dependente Opção pela mesma organização para novo estágio. Então, segundo o modelo, as variáveis independentes que mais influenciam a opção pela mesma organização para novo estágio são, por ordem decrescente: Proporcionou supervisão, Remuneração justa, Inserção em projetos e, de forma negativa, Oportunidade de efetivação.

Em ambos os modelos, a variável Oportunidade de efetivação apresentou coeficiente negativo, indicando que, quando maior a oportunidade de efetivação, são menores o atendimento das expectativas e a opção pela mesma organização para novo estágio. Esse resultado, de certa forma, não vai ao encontro do esperado, pois se esperava que, quanto maior a oportunidade de efetivação, maior o atendimento das expectativas. No entanto, tal quadro pode ser explicado pelo fato de os estagiários que acusaram maior oportunidade de serem efetivados terem desenvolvido atividades que não atendiam às suas expectativas. 
Tabela 6: Coeficiente e significâncias do modelo 2

\begin{tabular}{|c|c|c|c|c|c|c|}
\hline & \multirow{2}{*}{ Modelo } & \multicolumn{2}{|c|}{$\begin{array}{c}\text { Coeficientes não } \\
\text { padronizados }\end{array}$} & \multirow{3}{*}{$\begin{array}{c}\text { Coefic. } \\
\text { Padron. } \\
\text { Beta }\end{array}$} & \multirow{3}{*}{$\begin{array}{c}\text { t. } \\
-, 894\end{array}$} & \multirow{3}{*}{$\begin{array}{l}\text { Sig. } \\
, 394\end{array}$} \\
\hline & & \multirow{2}{*}{$\begin{array}{c}\text { B } \\
-1,681\end{array}$} & \multirow{2}{*}{$\begin{array}{c}\begin{array}{c}\text { Erro } \\
\text { Padrão }\end{array} \\
1,880\end{array}$} & & & \\
\hline 2 & (Constante) & & & & & \\
\hline & Facilidade de obter & 201 & 191 & ,222 & 1,054 & ,319 \\
\hline & Promoção de socialização &,- 512 & ,386 &,- 437 & $-1,324$ & ,218 \\
\hline & Proporcionou treinamentos &,- 088 & 314 &,- 091 &,- 280 & ,786 \\
\hline & Proporcionou supervisão &, 526 & 231 &, 550 & 2,277 & 049 \\
\hline & Inserção em projetos & 411 & 198 & ,379 & 2,083 & ,067 \\
\hline & Permitiu feedback &,- 519 & ,467 &,- 511 & $-1,111$ & 295 \\
\hline & Forneceu informações & 688 &, 503 & 623 & 1,367 & 205 \\
\hline & Aplicação do conhecimento & 065 & 312 & 047 & 208 & 840 \\
\hline & Relação com curso & ,094 & 312 & 077 & ,301 & 770 \\
\hline & Obteve novos conhecimentos &,- 015 & 303 &,- 012 &,- 049 & ,962 \\
\hline & Oportunidade de projeto & 312 & 190 & 370 & 1,641 & 135 \\
\hline & Disponibilizou equipamentos &,- 460 & 320 &,- 406 & $-1,435$ & 185 \\
\hline & Supervisor com formação &,- 088 & 159 &,- 082 &,- 555 &, 593 \\
\hline & Ofereceu desenvolvimento &,- 027 & 231 &,- 029 &,- 115 & ,911 \\
\hline & Facilidade de conciliação prática-teoria & ,226 & 233 & 191 & ,970 & ,358 \\
\hline & Oportunidade de efetivação &,- 393 & 172 &,- 511 & $-2,283$ & 048 \\
\hline & Integrantes atenciosos & ,846 & ,547 &, 559 & 1,545 & 157 \\
\hline & Ofereceu motivação & 125 &, 524 & 104 & 238 & 817 \\
\hline & Remuneração justa & ,424 & 203 & ,496 & 2,094 & 066 \\
\hline & Política de remuneração justa &,- 061 & 109 &,- 089 &,- 556 &, 592 \\
\hline & Recebeu orient. necessárias do supervisor &,- 269 & ,273 &,- 240 &,- 983 & ,351 \\
\hline & Recebeu orient. necessárias do orientador & 177 & ,263 & , 168 & ,675 &, 516 \\
\hline
\end{tabular}

a: Variável dependente Opção pela mesma organização para novo estágio

\section{Considerações Finais}

Cabe destacar, dos resultados identificados, aspectos positivos e negativos dos estágios oferecidos a alunos do curso de Administração Pública na modalidade a distância da UFVJM. Entre os aspectos positivos, os estagiários mostraram satisfação com a cordialidade e com a atenção dos demais integrantes das organizações concedentes. Desse modo, os resultados demonstram que tais organizações estão cumprindo esse quesito, considerado de suma importância para o progresso do estagiário. Outros pontos julgados de forma positiva foram: a possibilidade de articulação dos conhecimentos obtidos na graduação e a possibilidade de obtenção de novos conhecimentos por meio da prática. A supervisão, a orientação e a tutoria recebidas também foram bem avaliadas.

A média mais baixa obtida na pesquisa foi identificada no quesito recebimento de auxílio financeiro. A pesquisa também apontou que, em sua maioria, as organizações não possibilitam a inserção dos estagiários em seu quadro permanente de pessoal, assim como oportunidades para inserção em (ou desenvolvimento de) projetos. Na Educação a Distância, esse quadro reforça algumas críticas identificadas no referencial teórico sobre o fato de o estágio ser utilizado como estratégia para obtenção de mão de obra barata, sem permitir a aprendizagem de conhecimentos diretamente vinculados ao curso e à inserção permanente do estagiário no mercado de trabalho. 
Observou-se, com a análise de regressão múltipla, que a variável dependente Atendimento das expectativas, por ordem de influência, é explicada pelas variáveis independentes Fornecimento de informações, Remuneração justa, Disponibilização de equipamentos, Oportunidade em projeto, Supervisão e Inserção em projetos. Em decorrência, cabe aos intervenientes prestar atenção às variáveis citadas para que sejam atendidas as expectativas dos estagiários.

Por fim, cabe ressaltar as medidas julgadas necessárias pelos alunos para melhoria do estágio no âmbito do curso de Administração Pública da UFVJM. Foi apontada a necessidade de medidas que possibilitem o esclarecimento de dúvidas gerais e sobre a documentação necessária à realização do estágio e maior celeridade no preenchimento e assinatura dos documentos necessários. Também foi ressaltada a necessidade de maior interação entre os órgãos públicos e a universidade para que seja facilitada a inclusão dos estagiários.

Percebe-se, pelas demandas dos discentes, que a comunicação ainda é um fator que precisa ser melhorado, por ser essencial nos processos de interação e esclarecimento das informações. Como destacado por Martins et al. (2017) e Barbosa (2018), lidar com essa debilidade parece ser ainda mais desafiante em um contexto em que a distância geográfica é a principal característica da prática de ensino e de aprendizagem.

Entre as limitações deste estudo, cabe destacar o fato de a pesquisa quantitativa utilizar predominantemente questões objetivas; nesse caso, os respondentes puderam apenas concordar ou discordar das afirmativas propostas. Desse modo, podem ter ficado ocultas outras percepções e atitudes não previstas pelo pesquisador.

Como este estudo não se esgota em si mesmo, recomenda-se para sua continuidade que seja ampliado o escopo da análise a outros cursos oferecidos na modalidade EaD e a outros contextos geopolíticos. Recomendam-se também estudos comparativos com estagiários de cursos a distância e de cursos presenciais para que sejam identificados aspectos convergentes e divergentes, tendo em vista mais conhecimentos para a intervenção contextualizada. Ademais, pode-se realizar uma pesquisa qualitativa abordando os aspectos citados e averiguando se os resultados convergem com aqueles da análise quantitativa.

\section{Referências}

ABREU, Y. I. F.; MENERGON, L. F.; ANDRADE, J.; MARCELO, M. “Se você é motivado, pró-ativo e tem paixão por resultados...": análise de conteúdo de anúncio de estágio e trainee. XXVIII Encontro da Associação Nacional dos Programas de Pós-Graduação em Administração (ENANPAD). Curitiba, PR, 2004.

ALBUQUERQUE, L. S.; SILVA, E. M. Pontos positivos e negativos do estágio na formação profissional dos estudantes de Ciências Contábeis da cidade de Caruaru-PE. XXX Encontro da Associação Nacional dos Programas de Pós-Graduação em Administração (XXX ENANPAD). Salvador, BA, 2006.

AQUINO, R. D.; TOMASSINI, R. Os estágios curriculares e suas representações sociais segundo os graduandos em Administração. XXXII Encontro da Associação Nacional dos Programas de Pós-Graduação em Administração (XXXII ENANPAD). Rio de Janeiro, RJ, 2008.

ARAÚJO, R. O.; OLIVEIRA, E. R.; VIEIRA, A. A. L. B. (2013). Estágio Supervisionado: uma análise sobre a importância do estágio para a formação acadêmica e profissional de estagiários. Revista Científica da Faculdade Darcy Ribeiro, v. 4, 2013. Disponível em: http://revista.facped.com.br/index.php/rcdr/ article/view/54

BARBOSA, M. W. Um panorama da pesquisa em disciplinas de estágio supervisionado em cursos superiores a distância no Brasil. Revista EaD em Foco, v. 8(1), 2018. Disponível em: http://dx.doi.org/10.18264/ eadf.v8i1.686. 
BITTENCOURT, V. A relevância da prática de estágio na modalidade de Educação a Distância. XVII Congresso Internacional ABED de Educação a Distância. Manaus, AM, 2011.

BRASIL. Lei n 11.788, de 25 de setembro de 2008. Dispõe sobre o estágio de estudantes. Curso de Graduação em Administração. Disponível em: http//www.ufvjm.edu.br/cursos/index.php?option=comcontent\&view=article\&id=119\&ltemid=598. Acesso em 15 fev. 2018.

CUSTÓDIO, T. V.; CARRÃO, A. M. R. Os impactos do estágio na formação do administrador. III Transformar e Seminário Franco Brasileiro de Pesquisa. Piracicaba, SP, 2012.

FERREIRA, K. R.; SANTOS, M. S. A importância do estágio supervisionado para a formação profissional do acadêmico de Administração da Fesar. Revista de Administração do Sul do Pará (Reasp), v. 4(2), Ed. Especial, 2017.

GIL, A. C. Métodos e técnicas de pesquisa social. 6ª ed. São Paulo: Atlas, 2008.

HAIR Jr., J. F. et al. Análise multivariada de dados. 5ª ed. Porto Alegre: Bookman, 2005.

LEAL, R. F. R. Estagiários e aprendizes. In: Manual de treinamento e desenvolvimento: processos e operações. São Paulo: Pearson Prentice Hall, 2006. p. 166-176.

MARTINS, C. Z. et al. Estágio não obrigatório na Educação a Distância. XXIII Congresso Internacional ABED de Educação a Distância. Foz do Iguaçu, PR, 2017.

OLIVEIRA, A. A. R.; LEITE FILHO, C. A. P.; RODRIGUES, C. M. C. Relações de trabalho em estágios: exploração ou aprendizagem? IV Simpósio de Excelência em Gestão e Tecnologia (IV SEGeT). Resende, RJ, 2007.

PIMENTEL, N. M. Educação a distância. Florianópolis: SEAD/UFSC, 2006.

SCALABRIN, I. C.; MOLINARI, A. M. C. A importância da prática do estágio supervisionado nas licenciaturas. Revista Unar, v. 7(1), 2013.

UFVJM - Universidade Federal dos Vales do Jequitinhonha e Mucuri. Cursos a distância. 2018. Disponível em: http://www.ead.ufvjm.edu.br. Acesso em: 10 jul. 2018.

UFVJM. Resolução n 32 - Consepe, de 21 de novembro de 2008. Estabelece as normas de estágio dos discentes dos cursos de graduação da Universidade Federal dos Vales do Jequitinhonha e Mucuri UFVJM.

\section{Agradecimentos}

O presente trabalho foi realizado com apoio da Coordenação de Aperfeiçoamento de Pessoal de Nível Superior - Brasil (Capes). 